\title{
EL FEMINISMO DE EMILIA PARDO BAZAN
}

\author{
por \\ JUAN PAREDES NUÑEZ
}

Emilia Pardo Bazán, cuyo conocimiento se reduce generalmente a unas pocas líneas en los manuales, donde en definitiva se viene a decir que nació en Galicia y que escribió Los Pazos de Ulloa y La Madre Naturaleza, es una de las figuras más injustamente tratadas por la literatura española. Y no sólo por sus contemporáneos, sino incluso desde la perspectiva crítica actual ${ }^{1}$. De ella se ha dicho de todo: que escribía a lo hombre, que se ponía los pantalones para escribir, que era aficionada en extremo a la novedad, a la moda, que era una métome en todo. ${ }^{2}$

Tal vez la causa de esta impopularidad y olvido haya que buscarla en los propios rasgos personales de la autora ${ }^{3}$ : mujer obesa, cuellicorta, de aire algo bovino -como recuerda Guillermo de Torre ${ }^{4}$ - miope, condesa, famosa, culta, independiente, y además buena escritora, y que se atrevió a meterse en terrenos tradicional y excluyentemente masculinos.

\footnotetext{
${ }^{1}$ En la actualización crítica que María del Pilar Palomo realiza de la Historia de la Literatura Española de Valbuena Prat (Barcelona, Gustavo Gili, 1983), destaca algunos trabajos que en la última década han venido a sacar a Emilia Pardo Bazán de la perspectiva parcial desde la que siempre había sido considerada.

${ }^{2}$ Vid. CLARIN: Folletos Literarios, VII, Museum, Madrid, 1890.

${ }^{3}$ Cfr. Robert OSBORNE: Vida y obra de Emilia Pardo Bazán, Mexico, 1964, p. 131.

${ }^{4}$ Del 98 al barroco, Madrid, Gredos, 1969, p. 240.
}

"CLADERNOS DE ESTUDIOS GALLEGOS", Tomo XL, Fascículo 105, Santiago 1992. 
De cualquiera de las maneras, la injusticia que se ha cometido con ella es flagrante. Causa tristeza pensar que tal vez si hubiera nacido en otro país su fama sería mucho más extensa y, sin duda alguna, estaría considerada como una de las figuras claves de la literatura nacional. Porque nos encontramos con una de las mujeres más extraordinarias de la pasada centuria y aún del siglo actual. Crítico, novelista, cuentista, autora de infinidad de crónicas, impresiones de viajes, artículos sobre la vida contemporánea ${ }^{5}$, conferenciante incansable, miembro de numerosas sociedades, Consejero de Instrucción pública, catedrático... y, por encima de todo, y en palabras de Unamuno: mujer singular [que] nos ha dejado, entre otras lecciones, las de una laboriosidad admirable y la de una curiosidad inextinguible ${ }^{6}$.

Incansable, batalladora, está en todas partes. En las páginas de los períodicos, en los ecos de sociedad, en los escaparates de los libreros,... hasta en la sopa. La inevitable, la imprescindible doña Emilia, No hay entierro en el que no lleve su vela correspondiente, las más de las veces sin que se la den ${ }^{7}$. Dama obispal de la literatura española la llama Gómez de la Serna, y cuenta de su popularidad, cuando se la comparaba con uno de aquellos tranvías rojos madrileños -cangrejos-, porque también ella pasaba por Lis$t a^{8}$. Mujer eminentemente cosmopolita, en lugar de quedarse anquilosada en su terruño (como un Pereda en su montaña), vive en Madrid, donde lleva una intensa vida social. Viaja a Francia, Italia, Portugal, Bélgica, etc., -y ahí quedan como testimonio sus libros de viajes Al pie de la torre Eiffel, Cuarenta días en la exposición, Por la Europa católica, Mi romería, etc.,-; llevada de su afán de saber, aprende idiomas: francés, inglés, alemán, italiano, etc.; conoce a todas las personalidades literarias de su época, discute con Víctor Hugo, asiste al desván de los Goncourt, donde se reúnen Zola, Daudet, y los jóvenes Maupassant, Rod, Alexis..., la espada, la mala y el basto -según sus propias palabras- de la moderna novela francesa; introduce en España el naturalismo, provocando una estruendosa polémica -esa eterna compañera que no le abandonará durante toda su vida- con la

\footnotetext{
${ }^{5}$ Según Carmen BRAVO-VILLASANTE doña Emilia escribió más de mil quinientos artículos periodísticos. (Emilia Pardo Bazán y el periodismo, Revista, Instituto José Cornide de Estudios Coruñeses, núm. 7, 1971, p. 81).

${ }^{6}$ Recuerdos personales de Doña Emilia, Nuevo Mundo, 27 de mayo de 1921.

${ }^{7}$ Vid. Emilio BOBADILLA (Fray Candil): Pedanterías de Doña Emilia, Triquitraques Críticos, Madrid, 1892, p. 133.

${ }^{8}$ Nuevos retratos contemporáneos, Buenos Aires, Ed. Sudamericana, 1945, p. 145.
} 
publicación de La cuestión palpitante; da a conocer a los novelistas rusos con su estudio sobre La revolución y la novela en Rusia; publica una ingente cantidad de artículos sobre los temas más diversos, algunos de los cuales aún hoy conservan una palpitante realidad; pronuncia conferencias en el Ateneo y otros centros; se relaciona con todas las celebridades de su tiempo, con ellos habla, y si hace falta con ellos discute, siempre en la líena de fuego para defender sus ideas feministas, sociales, etc.; condesa, Consejero de Instrucción Pública, presidente de la sección de literatura del Ateneo..., y aunque la lista podría continuarse, baste decir que ahí están, para terminar, sus novelas y cuentos.

Y todo ello enmarcado en una decidida vocación didáctica, que constituye uno de los rasgos más característicos de su personalidad. Por eso escribe sobre Darwin, los poetas épicos cristianos, San Francisco, don Carlos, el Papa, la mujer española, el divorcio, el indulto, la pena de muerte, la cocina regional, la exposición de París, la España pintoresca, o la electricidad. Y por eso quiere explicar lo que es el naturalismo de la nueva escuela francesa, y dar a conocer a los novelistas rusos, y a Stuart Mill, y funda la Biblioteca de la mujer, y la Sociedad del Folklore gallego, escribe cerca de dos mil artículos, preside la sección de literatura del Ateneo, es Consejero... y, cómo todavía parece que le queda tiempo, funda el Nuevo Teatro Crítico, revista enteramente escrita y dirigida por ella, donde sólo pretende dar a conocer toda la vida política, social y cultural de su época. Tal vez el símbolo de esta febril inquietud pueda quedar resumido, al final de su vida, con su incorporación directa a las tareas académicas como primera catedrático de Literatura Contemporánea de las Lenguas Neolatinas de la Universidad Central de Madrid. De esta manera, su vida termina como empezó: Desde los artículos de divulgación de la ciencia amena a sus últimas lecciones sobre la literatura francesa moderna, es un único camino el recorrido: el esfuerzo ilusionado y combativo en busca de la verdad. Y ello sin tener en cuenta su gigantesca y extraordinaria obra narrativa ${ }^{9}$.

Con todo, tal vez su faceta más decididamente progresista fue su constante y activa preocupación por el tema de la promoción social y cultural de

\footnotetext{
${ }^{9}$ Independientemente de sus novelas, Emila Pardo Bazán, con sus cerca de seiscientos cuentos, se configura como uno de los cuentistas más prolíferos que ha producido la literatura universal de todos los tiempos. (Vid. J. PAREDES NUÑEZ: Los cuentos de Emilia Pardo Bazán, Universidad de Granada, 1979).
} 
la mujer. Reivindicación por la que luchó -como lo hicieron los krausistas y su misma paisana Concepción Arenal- durante toda su vida, y no sólo con su obra, sino con su propio ejemplo. Este aspecto ayuda a explicar su amistad con Giner de los Ríos, Castelar y otras personalidades, con las que no estaba de acuerdo en puntos trascendentales, pero a las que se sentía unida en una actitud común de defensa de los derechos de la mujer ${ }^{10}$.

Su conciencia feminista despertó muy tempranamente, alentada, en buena medida -como ella misma confiesa-, por la ayuda comprensiva de su padre, que siempre impulsó sus inclinaciones:

Mi inolvidable padre, desde que yo puedo recordar cómo pensaba (antes de que yo pudiese asentir con plena convicción a su pensamiento), profesó siempre en estas cuestiones un criterio muy análogo al de Stuart Mill, y al leer las páginas de La esclavitud femenina, a veces me hieren con dolorosa alegría reminiscencias de razonamientos oídos en la primera juventud, que se trocaron en diálogos cuando comenzó para mí la madurez del juicio (...) Y repito que así le oí opinar desde mis años más tiernos, de suerte que no acertaría a decir si mi convicción propia fue fruto de aquélla, o si al concretarse naturalmente la mía, la conformidad vino a corroborar y extender los principios que ya ambos llevábamos en la médula del cerebro ${ }^{11}$.

\footnotetext{
${ }^{10}$ En su artículo Don Francisco Giner dice: Nació nuestra amistad, no de similitud de ideas, sino, por su parte, de un generoso interés hacia mi trabajo, y por la mía del conocimiento de la suma bondad de aquella escogida alma (...). Era Giner resueltamente feminista. Todo lo que atañía al mejoramiento de la condición de la mujer le interesaba en el más alto grado. Por él conocí la famosa obra de Stuart Mill, La esclavitud femenina, que tanto influyó en el movimiento feminista en Inglaterra y que hice traducir y publiqué en castellano, cuando aún creía, ilusionada, que pudiesen aquí importarles a alguien tales asuntos (La Lectura, t. I, marzo 1915). Muy vinculada al grupo de los krausistas y a Giner estaba también su paisana Concepción Arenal, quien en 1844 resumía la situación de la mujer en España en un estudio para la obra The woman question in Europe (Nueva York, Putnam's Sons). Doña Emilia le dedica un artículo: Concepción Arenal y sus ideas acerca de la mujer (Nuevo Teatro Crítico, núm. 26, enero 1893, pp. 269-304).

"Stuart Mill, Nuevo Teatro Crítico, año II, núm. 17, mayo 1892, pp. 41-76. Este artículo sirvió de prólogo a La esclavitud femenina de Stuart Mill, que doña Emilia publicó en el tomo II de la Biblioteca de la mujer.
}

"CUADERNOS DE ESTUDIOS GALLEGOS", Tomo XL, Fascículo 105, Santiago 1992. 
Pronto aprendió la enorme dificultad que representaba para una mujer con inquietudes el moverse en una sociedad excluyentemente masculina:

Apenas pueden los hombres formarse idea de lo difícil que es para una mujer adquirir cultura autodidáctica y llenar los claros de su educación. Los varones, desde que pueden andar y hablar, concurren a las escuelas de instrucción primaria; luego al Instituto, a la Academia, a la Universidad, sin darse punto de reposo, engrana los estudios (...). Todo ventajas, y para la mujer, obstáculos todos ${ }^{12}$.

Pero los obstáculos no la amedrentaron nunca. Adquirió una considerable cultura -en los libros está su Universidad, y los autores son sus maestros- ${ }^{13}$, alcanzó la fama literaria, consiguió ser admitida como primera socio de número en el Ateneo (1895), donde más tarde preside la sección de literatura (1906), fue Consejero de Instrucción Pública (1910), socio de número de la Sociedad Económica Madridense de Amigos del País (1912), primera catedrático de Literaturas Románicas (1916), y a punto estuvo de ingresar en la Academia de la Lengua, solicitud que implicaba más una reivindicación de su sexo que una postura personal:

Si a título de ambición personal no debo insistir ni postular para la Academia, en nombre de mi sexo creo que hasta tengo el deber de sostener, en el terreno platónico, la aptitud legal de las mujeres "que lo merezcan" para sentarse en aquel sillón, mientras haya Academias en el mundo ${ }^{14}$.

La tentativa frustrada no hace sino fortalecer su convicción profunda y su seguridad. Muy ilustrativa a este respecto resulta la anécdota que nos cuenta Carmen Bravo-Villasante, cuando, con motivo de la recepción de Barbieri en la Academia, don Juan Varela, que también había querido intervenir directamente en esta nueva cuestión académica, para darle el golpe de gracia, con su folleto las mujeres y las Academias, invita a las

\footnotetext{
${ }^{12}$ Apuntes autobiográficos.

${ }^{13}$ Carmen BRAVO-VILlaSANTE: Vida y obra de Emilia Pardo Bazán, Madrid, Revista de Occidente, 1962, p. 39.

${ }^{14}$ Nuevo Teatro Crítico, núm. 3, marzo 1891.
}

"CUADERNOS DE ESTUDIOS GALLEGOS", Tomo XL, Fascículo 105, Santiago 1992. 
señoras que están de pie a ocupar los sillones vacíos por la ausencia de algunos académicos y doña Emilia, con mucha picardía, le contesta: Gracias, don Juan. Ya nos sentaremos en ellos algún día las mujeres por derecho propio ${ }^{15}$.

Y todo en el ambiente de polémica de una sociedad excluyentemente masculina, que no podía perdonar todo esto a una mujer; y una mujer que no sólo se contentaba con codearse con los literatos de su época, sino que en cuanto podía les pisaba el terreno, y que lo mismo hablaba de Feijoo que sobre Zola, Darwin, don Carlos, o el Papa; y sin dejar, además, de publicar sus novelas y cuentos.

Su lucha privada fue siempre acompañada de una ardua labor reivindicatoria y propagandística. En sus continuos viajes a Francia frecuenta los círculos feministas, está al tanto del movimiento sufragista inglés, se entera de la marcha del movimiento en los Estados Unidos y, confrontando la situación de la mujer en estos países con la de la mujer española, se lanza a su campaña.

En La España Moderna publica una serie de artículos sobre La mujer española, aparecidos poco antes en la Fortnightly Review, que constituyen un interesantísimo estudio para descubrir el verdadero perfil feminista de la autora, y un valioso documento sobre la situación de la mujer española de la época ${ }^{16}$.

Una idea central parece recorrer todo el trabajo: la mujer es lo que el hombre ha querido que sea, y esta dependencia atenúa, en buena medida, su responsabilidad. Víctima de una precaria educación y sometida a continuas limitaciones, lejos de marchar acorde con el progreso, la mujer ha sufrido una involución, especialmente a partir del siglo XVIII, que le ha hecho perder sus ideales, sin poder reemplazarlos por otros nuevos, patrimonio exclusivo del hombre, que con cada conquista en el terreno de las libertades no ha hecho sino ensanchar aún más el abismo existente entre él y la mujer.

$\mathrm{Al}$ hablar de la mujer española de su época, doña Emilia pasa revista a las diferentes clases sociales y los diversos tipos que produce:

${ }^{15}$ Op. cit., p. 162.

${ }^{16}$ La España Moderna, año II, núms. XVII, XVIII, XIX, XX, Madrid, 1890. Vid. Emilia Pardo Bazán, La mujer española y otros artículos feministas, selección y prólogo de Leda SCHIAVO, Editora Nacional, Madrid, 1976. Realizamos las citas por esta edición.

"CUADERNOS DE ESTUDIOS GALLEGOS", Tomo XL, Fascículo 105, Santiago 1992. 
Sus simpatías están con la mujer del pueblo. Según ella, la única clase que ha sabido conservar el carácter nacional. Subraya su originalidad y espontaneidad y sobre todo su condición trabajadora:

La hija del pueblo, chiquita aún, aprende ya a agenciarse el pedazo de pan haciendo recados, sirviendo, cosiendo, en la fábrica de tejidos, en la de cigarros, pregonando sardinas o legumbres, llevando las vacas al pasto o labrando la tierra.

Cada una de estas ocupaciones queda perfectamente ilustrada en sus novelas y cuentos. Baste citar, a modo de recordatorio, el ejemplo monumental de La Tribuna.

De los diferentes tipos populares femeniles, destaca la campesina, cuyo ejemplo más claro lo constituye la gallega -figura a la que siempre dedicó una atención y un cariño muy especial ${ }^{17}$-, y la obrera y la industrial catalana, símbolos de la mujer nueva de la civilización moderna.

El polo opuesto está representado por la aristocracia, en su opinión la clase más injustamente tratada. Ella asume su defensa, que de alguna manera era la suya propia, aunque no puede por menos que criticar su ociosidad y superficialidad.

Sin embargo su crítica más severa va dirigida contra la mujer de la clase media, de la que hace una pintura realmente demoledora. Le reprocha su falta de originalidad y espontaneidad, su holgazanería, su incultura, la mediocridad de sus aspiraciones, su cursilería y ridiculez, su absurda imitación de la aristocracia, ese continuo quiero y no puedo, su estrechez de miras y falta de energía, que explican la dócil aceptación del estado de dependencia e inferioridad en que vive:

¿Ejercer una profesión, un oficio, una ocupación cualquiera?. ¡Ah!. Dejarían de ser señoritas ipso facto (...). Quédense en la casa paterna, criando moho, y erigidas en convento de monjas sin vocación: viendo deslizarse su triste juventud, precursora de una vejez cien veces más triste; reducidas a comer mal y poco, a sufrir mil privaciones, para lograr sus objetivos en que fundar su única

\footnotetext{
${ }^{17}$ Cfr. nuestro trabajo La realidad gallega en los cuentos de Emilia Pardo Bazán (1851-1921), Edicións do Castro, La Coruña, 1983.
}

"CUADERNOS DE ESTUDIOS GALLEGOS", Tomo XL, Fascículo 105, Santiago 1992. 
esperanza de mejor porvenir. Primero, que tengan carrera los hermanos varones y puedan "hoy o mañana" servirlas de amparo; segundo, no carecer de cuatro trapitos con que presentarse en público de manera decorosa, a ver si parece el ave fenix, el marido que ha de resolver la situación (...) La modesta familia mesocrática escatima los garbanzos del puchero a trueque de que las niñas se presenten en paseos, teatros y reuniones bien emperejiladas con todos los aparejos convenientes para la pesca conyugal.

Esta triste realidad es la que doña Emilia ha dejado patente en su obra, y de manera particular en alguno de sus cuentos, que constituyen, en su cruel veracidad, un testimonio de la miserable situación y el precario porvenir de las muchachas de la pequeña burguesía. Así, por ejemplo, el titulado La manga ${ }^{18}$, en el que una intempestiva tormenta estival viene a destruir el sombrero -el susto y la ruina de una familia burguesa (...), un desequilibrio en el presupuesto, la supresión durante dos meses del plato de carne en la cena-Y el remendado, pero aparente, atuendo de una joven provinciana, destrozando al mismo tiempo todas sus ilusiones, al quedar ridiculizada y profanada ente los ojos del novio que acababa de encontrar. Ya no volvió más al paseo. Para qué. Era el triste drama de tantas señoritas pobres. No podía reemplazar la ropa perdida... Ni el novio, perdido al mismo tiempo que la ropa. En algún caso, como en Los ramilletes, el final es más duro aún. ${ }^{19}$

Doña Emilia contempla, con tristeza, la miserable situación de estas mujeres y la de tantas familias de la clase media, que un falso pundonor mantiene en la estrechez para salvar las apariencias. Pero lo que más le preocupa sin duda alguna, es la estupidez de las costumbres de la época en materia de educación femenina:

Siendo el matrimonio y el provecho que reporta la única aspiración de la burguesa, sus padres tratan de educarla con arreglo a las ideas o preocupaciones del sexo masculino (...). Este sistema educativo, donde predominan las medias tintas, y donde se evita como un sacrilegio el ahondar y el consolidar, da un resultado inevitable: limita a la mujer, la estrecha y reduce, haciéndola más pequeña aún

\footnotetext{
${ }^{18}$ Blanco y Negro, núm. 999, 1910.

${ }^{19}$ Blanco y Negro, núm. 999, 1908.

"CUADERNOS DE ESTUDIOS GALLEGOS", Tomo XL, Fascículo 105, Santiago 1992.
} 
que el tamaño natural, y manteniéndola en perpetua infancia.

En esta errónea concepción de la educación femenina está el germen de numerosos fracasos en el terreno conyugal. La falta de formación, o más bien la deformación, limitan considerablemente la libertad y el horizonte de elección de estas muchachas, que terminan aceptando al primero que se les acerca o al novio concertado por sus padres; sin contar con los numerosos casos de matrimonio por interés, a juzgar por los relatos de doña Emilia ${ }^{20}$. Un caso particular y muy interesante a este respecto lo constituye el cuento titulado La aventura ${ }^{21}$, historia de una pobre muchacha, sometida al peso de esta nefasta educación femenina, que prefiere escapar del hogar paterno antes que sacrificar, inútilmente, sus inquietudes y aspiraciones, aceptando el marido que sus padres le imponían. Esta es la mujer nueva que doña Emilia propugnaba y cuya figura quiso dejar esbozada, idealmente, en el personaje de Feíta.

Ella siempre defendió la igualdad del hombre y la mujer en todos los terrenos. Por eso critica duramente a una sociedad que ha establecido un baremo moral distinto para medir la conducta del hombre y la mujer. Algunos de sus cuentos, que bien podríamos calificar como literatura de denuncia, son una taxativa condena de esta situación. Así el titulado La culpable ${ }^{22}$, historia de una pobre mujer a quien la conducta dilatoria de los padres con respecto a su casamiento, obligó a escapar con el que hoy es su marido, y a quien la sociedad no perdona su falta, a pesar de su intachable conducta. Incluso su marido, que por otra parte disfruta de la hacienda a su antojo para sus deslices y diversiones, la tiene en menos consideración por aquella debilidad. La crítica es durísima contra esa sociedad que reprueba con dureza implacable en la mujer las mismas acciones que es capaz de reír y celebrar en el varón. En alguna ocasión fue incluso más allá, atreviéndose ¿ tocar ciertos asuntos que difícilmente hubiera podido tratar de otra manera. Así ocurre en La novia fiel ${ }^{23}$, donde aborda el delicado tema -téngase en cuenta la fecha de publicación- de las relaciones prematrimoniales.

\footnotetext{
${ }^{20}$ Sobre este tema tratan algunos cuentos como Champaña, La boda, Los cirineos, Banquete de boda, etc.

${ }^{21}$ Blanco y Negro, núm. 406, 1899. Recogido en la serie Cuentos dramáticos.

${ }^{22}$ El Liberal, 25 de septiembre de 1893. Recogido en la serie Cuentos de amor.

${ }^{23}$ El Liberal, 11 de febrero de 1894. Recogido en Cuentos de amor.
}

"CUADERNOS DE ESTUDIOS GALLEGOS", Tomo XL, Fascículo 105, Santiago 1992. 
Según doña Emilia, la liberación de la mujer sólo podría conseguirse a través de una sólida y completa educación, como expresó claramente en el Congreso pedagógico celebrado en Madrid en 1892. Allí se discute si la mujer tiene derecho a recibir la preparación suficiente para el desempeño de todas las profesiones. El resultado no puede ser más significativo: 260 votos a favor, 293 en contra y 89 abstenciones ${ }^{24}$. En este contexto lee Emilia Pardo Bazán su Memoria La educación del hombre y la mujer, sus relaciones y diferencias ${ }^{25}$, en la que defiende ardorosamente el derecho de la mujer a recibir una educación íntegra y a ejercer una profesión en igualdad de condiciones que el hombre. Para tener una idea de cuál era realmente la situación de la mujer en España en estos momentos baste decir que la primera estudiante de la Facultad de Filosofía y Letras de Madrid, María Goyoi, se matriculó en 1891 gracias a un permiso especial de las autoridades. Sólo a partir de 1910 -fecha en que Emilia Pardo Bazán es nombrada Consejero de Instrucción Pública- pudo la mujer matricularse libremente en la Universidad. Todavía en 1892 necesitan las señoras una invitación de la junta de gobierno para asistir a las veladas del Ateneo. Claro que tres años más tarde doña Emilia es admitida como primera socio de número y da sus conferencias sobre literatura contemporánea, que fueron de las que más y más dintinguido público de ambos sexos llevaron al Ateneo ${ }^{26}$.

Una de las mayores contribuciones de Emilia Pardo Bazán a esta campaña educativa propugnada por ella en el Congreso de Madrid fue la publicación, comenzada en el mismo año, de la Biblioteca de la mujer, donde incluye trabajos tan importantes como La esclavitud femenina de Stuart Mill o La mujer ante el socialismo de August Bebel.

Sin embargo no siempre mantuvo este ardor polémico y combativo, y ya en 1913 -desengañada de sus ideales- da un brusco cambio a la Biblioteca, donde ahora publica La cocina española:

Cuando yo fundé la Biblioteca de la mujer, era mi objeto difundir en España las obras del alto feminismo extranjero, y por eso di

\footnotetext{
${ }^{24}$ Vid. Condesa de CAMPO ALANGE: La mujer en España. Cien años de su historia, 1860-1960, Madrid, Aguilar, 1964. Citado por Leda SCHIAVO, op. cit., p. 20.

${ }^{25}$ Memoria leída en el Congreso pedagógico el día 16 de octubre de 1892. Recogida en el Nuevo Teatro Crítico, año II, núm. 22, octubre de 1893, pp. 14-82.

${ }^{26}$ Vid. Leda SCHIAVO, op. cit., p. 14.
}

"CUADERNOS DE ESTUDIOS GALLEGOS", Tomo XL, Fascículo 105, Santiago 1992. 
cabida en ella a La esclavitud femenina de Stuart Mill, y a La mujer ante el socialismo de Augusto Berbel. Eran aquellos los tiempos apostólicos de mi interés por la causa. He visto, sin género de duda, que aquí a nadie le preocupan gran cosa tales cuestiones, y a la mujer, aún menos. Cuando, por caso insólito, la mujer española se mezcla en politica, pide varias cosas asaz distintas, pero ninguna que directamente, como tal mujer, le interese y convenga. Aquí no hay sufragistas, ni mansas ni bravas. En vista de lo cual, y no gustando de luchar sin ambiente, he resuelto prestar amplitud a la Sección de Economía doméstica de dicha Biblioteca, y ya que no es útil hablar de derechos y adelantos femeninos, tratar gratamente de cómo se prepara escabeche de perdices y la bizcochada de almendra ${ }^{27}$.

Independientemente de estas fluctuaciones, correspondientes al período de desengaño de su última época, y dejando a un lado naturalmente las circunstancias concretas de su momento histórico, no cabe la menor duda que una buena parte de sus reivindicaciones feministas conservan aún hoy -justificando plenamente la postura de la autora- una compleja validez. Sería absurdo discutir ahora el derecho de la mujer a recibir una educación adecuada o ejercer cualquier profesión, pero un tema como el ingreso de la mujer en la Academia ha estado hasta hace poco en candelero, y otros, como el de las relaciones prematrimoniales o el divorcio, conservan una palpitante realidad.

Tal vez su feminismo estuvo un tanto limitado al no insertarse en una problemática política y social mucho más amplia, pero nadie puede dudar de la combatividad y audacia con que siempre defendió los derechos de la mujer, tomando a veces posturas que perfectamente pueden calificarse de radicales. Nuevamente hay que destacar aquí la modernidad de una autora, que no sólo supo vivir intensamente su tiempo, sino, en ocasiones, ganarle la partida y adelantarse a él.

${ }^{27}$ Carta a don Alejandro Barreiro, director de La Voz de Galicia, Publicada por BRAVO-VILLASANTE, op. cit., pp. 279-281.

"CUADERNOS DE ESTUDIOS GALLEGOS", Tomo XL, Fascículo 105, Santiago 1992. 